\title{
Communicating Corrected Risk Assessments and Uncertainty About COVID-19 in the Post-truth Era
}

\section{OPEN ACCESS}

Edited by:

Anabela Carvalho,

University of Minho, Portugal

Reviewed by:

Louise Jane Phillips,

Roskilde University, Denmark

Jennifer Manyweathers,

Charles Sturt University, Australia

*Correspondence:

Adalberto Fernandes

adalberto.castro.fernandes@gmail.com

Specialty section:

This article was submitted to

Science and Environmental

Communication,

a section of the journal

Frontiers in Communication

Received: 24 December 2020

Accepted: 22 March 2021

Published: 14 May 2021

Citation:

Fernandes A (2021) Communicating

Corrected Risk Assessments and Uncertainty About COVID-19 in the

Post-truth Era.

Front. Commun. 6:646066. doi: 10.3389/fcomm.2021.646066

\begin{abstract}
Adalberto Fernandes ${ }^{1,2 *}$
1 Department of History and Philosophy of Sciences, Centre for Philosophy of Science, University of Lisbon, Lisbon, Portugal,

${ }^{2}$ Center for Neuroscience and Cell Biology, University of Coimbra, Coimbra, Portugal
\end{abstract}

The COVID-19 pandemic has been a challenge for science communication in terms of addressing the question of uncertainty and how it translates into risk. This task has been aggravated by the complexity of the pandemic and the current post-truth environment. The article suggests that there is a need to analyze the practices of correcting risk information that is uncertain, but not necessarily false, made by online news media about COVID-19. This is a point of analysis where the uncertainty and risk linked to science, the pandemic, and the post-truth condition meet. The qualitative discursive analysis yielded three important results: (1) uncertainty can be fought by increasing uncertainty; (2) a multiplication of facts or reasons may not be the most prominent strategy in practices of correction; and (3) the use of hyperlinks with additional information can increase uncertainty and risk.

Keywords: COVID-19, science communication, risk, uncertainty, discourse analysis, actor-network-theory, posttruth

\section{INTRODUCTION}

COVID-19 has not only been characterized as a viral infection but also as an "infodemic" issue that has permeated the functioning of science communication with an abundance of information and misinformation (Pulido et al., 2020; Graham, 2021; Hope, 2021) ${ }^{1}$. Science communication is a theoretical and practical field in which questions of public health (Chen et al., 2020; Head et al., 2020) are intertwined with issues of uncertainty (Paek and Hove, 2020; Atherton, 2021; Grace and Tham, 2021) and risk during this pandemic (Chou and Budenz, 2020; Lovari, 2020; Batova, 2021). The questions of uncertainty and risk have, moreover, been aggravated by the socioeconomic complexity of the pandemic (Guan et al., 2020; van Barneveld et al., 2020). The complexity of the COVID-19 crisis has also been associated with the era of "post-truth," which had already complicated the relationship between science and society before the start of the pandemic and persists in the present moment (Meese et al., 2020; Patel et al., 2020; Koerber, 2021).

The science communication on COVID-19 is characterized by "uncertainty-risk" because the knowledge it discusses is open to falsifiability, meaning there is a risk of the information being disproven (Popper, 2002). However, such scientific uncertainty becomes more difficult to communicate due to the high risk of mortality and morbidity during a pandemic (Zhai et al., 2020). On the one hand, scientific uncertainty becomes more evident because it not only involves scientific reasoning but also political reasons and decisions that are beyond scientific evaluation, which increases the risk of unforeseen impacts (Guttman and Lev, 2020; Lasser et al., 2020). On

\footnotetext{
${ }^{1}$ The author wants to thank all the insightful suggestions of the Editor, Anabela Carvalho, and those of the two anonymous reviewers. The author is the only responsible for the weaknesses of the article.
} 
the other hand, during a pandemic, the communication of uncertainty has an impact on the management of risks because these can be aggravated or ameliorated by public behavior. The public is the object and means of contamination, and behavior of the public can change according to the information available about the virus (Post, 2016; Hendriks and Jucks, 2020; Hendriks et al., 2020). Thus, the article explores that the risks of the pandemic increase the uncertainty of science and its communication. In turn, the uncertainty of science and its communication aggravate the risks of the pandemic. The COVID-19 crisis has a communicational dimension, given that information about the pandemic is used in the public sphere as a way to deal with it. The communication of uncertainty at a time when people can die and lose their health correlates with risk because to be unsure about a thing that kills people creates the conditions that endanger life.

The situation of post-truth, which existed before the pandemic started and had already threatened the communication of scientific uncertainty, increases the communicational complexity of the present crisis because the authority of science is publicly challenged. Academic research about post-truth has been concerned with at least two versions of the phenomenon. Version 1: post-truth is understood as a form of deception that is usually associated with politicians who strategically distort knowledge to achieve certain power objectives (Waisbord, 2018). This manipulation is targeted at certain vulnerable public groups that are considered to be delusional, dogmatic, and ignorant (Bronstein et al., 2019). Version 2: post-truth is also understood as a period during which different epistemic projects that have been overlooked by science are reclaimed (Fuller, 2018). This opportunity arises once the notion that scientific knowledge can solve, with certainty, all political problems is questioned. Among those who feel neglected by science, it can be included people who demand a form of science that establishes a dialog with society and includes diverse types of knowledge to inform political decisions (Jasanoff and Simmet, 2017; Palliser and Dodson, 2019; Manyweathers et al., 2020). Such a dialog, among other things, demands the recognition of consequences related to the links that science has established with technological markets (Cooper, 2008) and military investments (Mukerji, 2014). More importantly, this second post-truth version recognizes that science is engaged in "power-knowledge relations" (Foucault, 1979). According to the Foucauldian thesis, science creates opportunities for the government to be more efficacious in its exercise of power by learning how to exercise it with less resistance. This exercise of power constitutes, in turn, a phenomenon that can itself be studied to improve that same dynamic. This point of view means that power does not only operate through violence, brutality, ideology, or deception but also through knowledge and being truthful, and using the best knowledge available. In version 2, the uncertainty is not destructive of science due to political motives but constitutes a moment to question the political implications that are associated with that uncertainty. If the certain knowledge constitutes an opportunity to exercise power intelligently, then uncertain knowledge is open to uncertain political effects, which can be dangerous. This means that the communication of science, which refers to the creation of public trust in scientific content that has a social impact (e.g., the reputation of scientific institutions, social attitudes toward science, public investment in science, and how the public should behave during a pandemic), already raises political issues. The communication of science thus constitutes an opportunity that can increase or decrease the power of scientific institutions over public matters.

One important moment of encounter between the challenges of uncertainty and risk can be found in the news media practice of "correcting" information about COVID-19. Corrections are needed not just because the scientific evidence has been proven wrong or false, but because the COVID-19 pandemic is complex in communicational terms. During the COVID19 crisis, science communication, risk communication, health communication, and political communication come together to produce a challenging mix (Guttman and Lev, 2020; Lasser et al., 2020). Another important reason for continued media efforts to correct information is that the scientific and biomedical evidence about COVID-19 is changing rapidly and constantly. As a result, scientific and biomedical institutions around the globe are concentrating on the production of knowledge about the novel virus (Zhai et al., 2020). The literature about the correction of scientific messages in the news shows that there is growing research focus on the topic of "fact-checking" (Graves, 2018; Amazeen, 2020). There is also relevant work about "apologies" in the media (Kampf, 2011; Opt, 2013; Ancarno, 2015), and there is a special focus on social media as a digital space for the correction of scientific information (Vraga and Bode, 2017; Smith and Seitz, 2019; Van Heekeren, 2020). However, there are few studies about the correction of scientific information in the news when what is in question is not to prove if a fact is true or false, or to present apologies for some wrong-doing, or to use social media strategies to fight misinformation. Our interest is rather in the reporting of the constant change in scientific evidence in the media, as is the case during this pandemic. The few existent studies on this topic are about the "swine flu" or the H1N1 influenza pandemic of 2009, and they claim that there was a lot of conflicting information (Klemm et al., 2016). The strategies to correct this information were motivated by a reductive journalistic framing of the complex risks of a pandemic (Chan, 2016). However, these studies do not focus on a detailed analysis of the corrected information. The research about media exposure of scientific retractions is the topic that is closer to the question of correcting of scientific information in the news (Sarathchandra and McCright, 2017). The information that is corrected in the media about COVID-19 is, however, not the result of a "retraction" of scientific results. In the COVID19 crisis, media are rather dealing with the emergence of new scientific evidence or new policy recommendations based on new evidence that makes previous results and policies outdated but not necessarily false.

The current gap about the correction of information in the media in the literature of communication studies, and especially in science communication, should be addressed because at this particular moment it has maximal relevancy. Especially now, science has to correct itself by creating a space where it can be publicly contested or praised for its capacity to correct 
itself. Science communication has to be able to deal with past information that is considered risky in the present and needs to be revisited, without raising or downplaying the risks that a pandemic situation brings. Given the complex character of the pandemic, the speed of the news, the constant production of scientific results, and the "post-truth" condition, it is necessary to analyze how the news media engage in corrective practices of information (Fu and Zhu, 2020; Krause et al., 2020). In other words, it is time for science communication of corrected risk (SCCR).

The concept of risk that informs this analysis is that of the sociologist Ulrich Beck. This author tells us that science and technology not only manage to control "natural" risks but also produce their own risks by incrementing technoscientific complexity and uncertainty in the world. The concept of risk of Beck is defined by a kind of an autogenetic and irreducible production of risk (Beck, 1992). Brian Wynne is another important author for the conceptualization of risk because he made a kind of "conceptual transfer" of the concept of risk of Beck into science communication (Wynne, 1998, 2002). Wynne suggests that when experts hide risks from the public and do not take into consideration the risk evaluation of non-experts about a dangerous situation, they raise the level of risk caused by the original situation. This scenario occurs because experts do not engage in open and dialogic communication during which additional knowledge about risks could be shared and debated from different perspectives (Wynne, 1992). Risk is, then, produced and negotiated during interactions. Taking these two considerations from sociology and science communication as a starting point, what I want to study is the level of risk that is produced by the communication of science. This is a "communicational risk" in the sense that science communication is an attempt to fight risks and, as a technique, it can produce other risks. These risks could be, for example, misunderstanding, an increase in uncertainty due to competing information, communicational self-fulfilling prophecies, and the legitimation of dubious political effects by scientific authorities. Communication is engaged in an irreducible production of risk, which means that I follow the contribution of Beck. This perspective also means that it is necessary to be attentive to the new risks that the correction of risk produce and to be moderately skeptical about any claim about the absence of risk. I also want to study, following Wynne, how the media try to incorporate different risks that are communicated by at least two parties: the corrected and the correcting one (this process can also apply to one actor correcting in the present its past affirmations of risk). I hope to find a discursive interaction about risk and how that interaction affects the degree of risk communication. Both understandings of risk, as irreducible and interactive, make the communication of uncertainty in COVID-19 a paradoxical mission, and thus it is this paradox that is investigated. We need to recognize that to communicate risk is always a communication of a risk that is irreducible. We cannot know everything that makes our behavior risky, but we can know that uncertainty is certain.

Given that risk is irreducible and can be augmented through the efforts of communication that try to manage it, this means that the SCCR will be a question of achieving equilibrium. The research problem that guides the article will be the following: How can we communicate a corrected risk associated with scientific topics without communicating an absence of risk or a certainty of risk? The absence of risk is impossible, given the argument of Beck, and the certainty regarding risk refutes the proper character of risk defined as a "certain incertitude." In other words, how do we correct risk in science communication with an acceptable level of risk? Put differently, how can we correct scientific information without associating the subsequent corrected communication with an absence of risk or an absolutization of the certainty of risk? The communication of information free from risk or presenting the inevitability of risk would defeat the very idea of risk, which is defined as a "certain incertitude." How do we deal in science communication with a form of uncertainty that cannot disappear completely without consequences for the open character of science and the overlooking of risks that stem from that openness, especially during a pandemic?

The SCCR can make a useful difference through its management of uncertainty. SCCR needs to analyze the uncertainty associated with the open, debatable, and falsifiable character of science, and how it relates to risks associated with that uncertainty. The moment of the correction of risk touches the heart of science understood as a process of debate and confrontation (Kuhn, 1970) to reach a temporary consensus that is always open to falsification (Popper, 2002). In this sense, by being an act of communication about a debatable and falsifiable science, science communication cannot but deal with that openness and uncertainty. As the philosopher of science, Stengers (2000) argues, to do a scientific experiment is to put oneself at "risk," to be open to failure, to face the uncertainty of success. However, it is this space of risk provided by the experiment that can prove something that is not entirely made up by the subject (an artifact) because it is also made by the experiment (a fact). During a pandemic, experimental "scientific risk" combines with socioeconomic risks and with risks that stem from post-truth. These double epistemic and political effects make scientific risk one of the most relevant topics in the correction of uncertainty for science communication. The communication and correction of uncertainty during a pandemic are about more than just transmitting scientific information. This process is a way of contributing to the political management of a public health crisis in individual and collective terms.

According to the second version of post-truth, the correction of risk will also be an opportunity to see how it opens up a space of debate concerning the political implications of the science that need to be rearticulated. Science communication is an example of a power-knowledge relation in action. The moment that a risk is corrected destabilizes the relations of power that were associated with a certain level of risk. This correction constitutes a singular moment to study the second version of post-truth, since the possibility to debate the new political significance of a risk is changing. It can, however, be made clearer how the posttruth condition of science communication, as a field that is always tied to certain power effects, relates to the lingering possibility of risk. Science has to be communicated in a way that preserves 
the possibility that it can be disproven in the future, that is, it is communicated with an irreducible level of uncertainty. It is, moreover, equally impossible to totally eliminate risk. Hence, the communication of an uncertainty-risk relation produces the power of telling who is at risk, who can escape that risk, what people should do to avoid risk, and what the consequences are of risk-taking. This power operates through the order of discourse that structures the pandemic world in terms of what modes of living are acceptable concerning different risks for different lives.

\section{MATERIALS AND METHODS}

The above-stated problem will be addressed through qualitative methods. This study utilizes three tools from Science and Technology Studies (STS): Semiotics of Science (Latour and Bastide, 1986), Rhetoric of Science (Bazerman, 1988), and ActorNetwork Theory (ANT) (Latour, 1996). These tools have already been used in Science Communication studies and have been associated with interesting results. Examples come from Lowrey and Venkatesan (2008) (semiotics), Myers (2003) (rhetoric), and Davies (2019) (ANT). Here, the original contribution will be the application of these qualitative methods to the SCCR. These three approaches are the conceptual tool boxes to analyze news media correction strategies of COVID-19 information.

The so-called linguistic turn (Rorty, 1992) in the academic world made the language more "thick" and less transparent by questioning the notion that a "neutral" medium exists to convey formless and non-linguistic independent content. As a result of this concern with the role of language as a medium that shapes the world, the linguistic production of certainty became important for those studying communication (e.g., Wittgenstein, 1991). In simple terms, we can say that to convey certainty to a message, we have to use language that is appropriate to that end, and the same thing holds for the production of uncertainty. Both are linguistic products, both of them need a certain syntax (order), semantics (meaning), and pragmatics (context) to exist. One important linguistic device that gives degrees of certainty to a message is "modality" (Latour and Woolgar, 1986, p. 77). A modal word is a linguistic element that can attribute more or less certainty to another word about what is claimed. For instance, there are degrees of certainty that can be translated as suggestion, possibility, or necessity: "we suggest that something will happen"; "it is possible that something happens"; and "it is necessary that something happens." The degree of certainty that something will happen in these three sentences changes with the use of these modalizers. Latour and Woolgar (1986, p. 77-80) tried to show semiotically that scientific sentences can be characterized as more or less factual through the type and number of modalizers used. A scientific fact would be, linguistically, a claim in which there are strong modalizers (e.g., "necessity"). If a fact is written with weak modalizers (e.g., possibility), it has a less factual character. One important insight from this semiotic approach is that a scientific fact with a strong modality equals a fact from a "scientific textbook." The scientific claim has become something that is considered as a given and can be taught in schools without much controversy (Latour and Woolgar, 1986, p. 76-77). This insight also means that cutting-edge science uses modalities that are not too strong. However, this type of science is the most relevant because it ventures into new knowledge in a highly competitive scientific system and is ready to destroy any strong modality. The semiotics of science, thus, shows that the strongest science is produced with uncertainty, with weak modalities. Thus, risk can discursively be studied as a case in point of modality. The study considers the contribution of Beck, who conceptualizes risk as something irreducible, that is, something that "can always" happen, characterized by a "possibility" of which the probability is "never" zero. Given that during a pandemic there is an "uncertainty-risk" relation, the semiotics of science is useful to treat uncertainty and risk as cases of modality because they never disappear completely and need to be discursively modalized. This state of affairs is especially true during a pandemic because scientific knowledge is constantly changing in response to the risks of the pandemic whose effects feed back into science.

To enrich the approach to semiotic modality, I will also analyze it from the perspective of the Rhetoric of Science. This field of study attempts to show that the communication of science between scientific peers is already a rhetorical achievement. The roles of ethos (the credibility of the author), logos (the reasons used), and pathos (the audience that analyzes author credibility and the reasons used $)^{2}$ - the three elements of Aristoteles's Rhetoric (Aristotle, 1984)-are crucial for any successful production of scientific knowledge (Bazerman, 1988). Latour and Woolgar (1986, p. 201) show this rhetorical dimension when they claim that science can be understood through "cycles of credit," where the credibility of scientists, institutions, scientific methods, and instruments mutually reinforce a "scientific capital." For instance, they noted that scientists in a lab simultaneously used different forms of credibility: "When I consider all the investment I made in this substance in the laboratory and I don't even have a good assay for it: If Ray is unable to set up this assay, he will be fired" (Latour and Woolgar, 1986, p. 199, my italics). The credibility of the substance is associated with the credibility of the assay, and the credibility of the assay is associated with the credibility of Ray. Rhetorically, the communication of science between peers already mobilizes ethos, logos, and pathos dimensions of discourse. The risk or uncertainty associated with scientific topics has effects beyond the scientific realm when the "confidence" or "reliability" of the results has to be translated into credibility in science by society. To communicate risk is to communicate more than scientific or epistemic risk (e.g., the risk of being wrong); it is also a political and social risk that stems from scientific uncertainty. SCCR, therefore, cannot just be "science" communication that is solely focused on the transmission of facts about COVID-19. In that sense, SCCR is directed at the publics outside the scientific realm and cannot escape from engaging with the rhetorical moves of ethos, logos, and pathos. Credibility, logic, and audiences are extremely

\footnotetext{
${ }^{2}$ This research follows the definition of pathos of the rhetorician, Meyer (2010, p. 407-408). Pathos means not just an audience who is persuaded through emotions or passions, but also the audience who must be persuaded with reasons from a credible source. Otherwise, the credibility and the reasons would not have any relevant persuasive function if the audience were just convinced with emotional appeals.
} 
important for the successful public communication of science (Fahnestock, 2020). For instance, the phrase "flatten the curve," meaning the reduction of the statistical count of infections and death by COVID-19, has been used as "a rhetorical anchor for communicating the risk of viral spread" (Amidon et al., 2021). Other rhetorical studies suggested that the elements of ethos and pathos have a prominent function when the science that is being communicated is associated with risk (Miller, 2003; Simon, 2020) or public contestation (Martini, 2018).

Finally, the article complements the semiotic and rhetorical analyses of modalization with the method of actor-network theory (ANT) in order to understand how modality materializes. Modality can be strengthened or weakened by material networks that can consist of, for example, human, textual, biological, architectural, or institutional elements. ANT is a social theory that tries to understand "whether or not a connection is established between two elements" (Latour, 1996, p. 372). These connections, networks, or linkages are made by "actors," defined broadly by ANT as "something that acts or to which activity is granted by others" (p. 373). ANT follows the lessons of ethnomethodology in the sense that the analyst has to follow the actors and concretely see their movements in order to understand how they interdefine each other and themselves (Latour, 1999, p. 19). ANT is a method that encourages us to search "a continuity, a multiplicity of plugs" between different types of actors-textual actors, social actors, or natural actors (Latour, 1996, p. 377-378). For instance, society can be defined in opposition to the natural (e.g., a building is not a tree) or in association with the textual (e.g., the Constitution gives social rights). What is important is that the analyst has to follow how these concepts interdefine each other, instead of presupposing that one of the actors is dictating unilaterally what the other is. However, Latour claims that these categories of the social, natural, scientific, and textual are "arbitrary cutting points on a continuous tracing of action" because the objective of ANT is to understand how these categories are made through a "network," a relational work, to "attribute 'textuality' or 'sociality' or 'naturality' to this or that actor" (Latour, 1996, p. 378-379).

The "second version" of post-truth, with its Foucauldian overtones, has a discursive-analytical counterpart. The study followed the invitation of Angermuller (2018), who claims that Discourse Studies should embrace the second version of posttruth. This invitation confirms the already politically oriented character of critical discourse analysis (CDA) that reclaims the heritage of Foucault (Wodak and Meyer, 2009). His discursivepower approach is laid out in Orders of Discourse, and he introduces the concept of power analytics in Discipline and Punish and in the first volume of the History of Sexuality. Foucault argues in his articulation of discourse and power, which will be highly influential for CDA, that discourse is a way of ordering experience and establishes who is allowed to talk, where, and when (Foucault, 1971). Additionally, Foucault reminds us that discourse is not an expression of adiscursive reality of power and knowledge relations. It is only in discourse that those relations can be articulated, which means that power does not only operate by silencing discourse or deception. If discourse is where knowledge and power are articulated, this means that power can also operate by making people speak. This results in incentivizing them to talk about themselves and to share their identities and secrets in order to know them better and to control them more efficiently and with less resistance (Foucault, 1978). Foucault shows that discourse is neither something that powerknowledge relations use after they are formed, nor that power silences the sound of knowledge. It is in discourse that power and knowledge operate, exist, and produce effects. We can also see that Foucault gives us a discursive thesis that is adequate for analyzing the second version of post-truth because it is through truth and knowledge that power and political effects happen, and not just through deception or silencing science.

It should be noted that, in terms of the discursive power of modality, there is an important research tradition in communication studies that are already trying to understand how this linguistic function produces relations of power. CDA profusely uses the linguistic analytics of modality proposed by the linguistics scholar Michael Halliday. The work of Halliday enters CDA through the Critical Linguistics (CL) of Hodge and Kress that resulted in contemporary CDA (Wodak and Meyer, 2009). CDA is characterized by the inclusion of other political theories besides the Marxism of CL, namely a Foucauldian analytics of power. Although the larger field of communication studies, which includes media studies or risk communication, has studied modality, the modality has not received systematic attention in the specialized field of the public communication of scientific topics with risk impacts. There is valuable work in discourse studies about Science Communication, including science associated with risk (Tollefson, 2014; Maeseele, 2015). There are research studies in the field of science communication that uses discursive approaches, including studies that focus on the question of modality (Stamou et al., 2009; Simmerling and Janich, 2016). However, there is a lack of discursive approaches to the public communication of scientific topics subjected to the correction of risk information that uses modality as an analytical tool. The research that uses modality to study the public communication of scientific matters, which is not about risk correction, claims that weak modality is used to reduce the certainty of what is being communicated (Motta-Roth and dos Santos Lovato, 2011; Szymanski, 2016). The power implications of such a move, however, have not been further explored. The power effects of modality are only taken into account when a strong modality (e.g., certainty) is used illegitimately to impose a scientific vision as unquestionable (Stamou et al., 2009; Heffernan et al., 2011; Nhung, 2018), which is closer to the first version of post-truth.

However, the modality of scientific discourse in the public sphere has a nuanced power function that asks for a specific discursive approach. Instead of following the linguistic research program of Halliday, the semiotics of science follows the French semiotic tradition of Algirdas Greimas (Latour, 1996), which is combined with the Foucauldian thesis of power-knowledge relations (Latour and Woolgar, 1986, p. 229). This incorporation turns the study of modality into a powerful instrument to analyze scientific discourse. According to Latour and Woolgar, the institutional credibility and monetary credit stem from the credibility that science produces with its discursive modalizers, 
which depend on the credibility of the instruments and the researchers, which in turn needs institutional and monetary credit to exist (Latour and Woolgar, 1986, p. 201). For example, a strong modality in a scientific statement can be necessary to obtain a grant but can reduce the credibility of the researcher among their peers. Experiments of cutting-edge science do not warrant strong modalities and, without peer legitimacy, funders will not trust strong modalities. So why use the semiotics of science instead of the CDA approach to modality? First, the semiotics of science of Latour and Woolgar already incorporates a power dimension by relating the modality of scientific statements with institutional power and money. Second, the question of modality in scientific topics is different from the themes traditionally studied by CDA (ideology, media, gender, race, etc.). The scientific discourse asks for a modalization that encapsulates a specific risk that has a double character: (1) the risk of being falsified, and (2) the risk of not being able to be falsified (which is an essential element of scientificity). In CDA research and other discursive approaches to science communication, the study of modality concerns cases in which the modality is made stronger (necessity of something or certainty) to hide the subtle and complex meaning of a reality that is usually composed of possibilities and probabilities rather than inevitabilities. This kind of strong modalization is explained by the need to obtain power through that simplified reality (Stamou et al., 2009; Nhung, 2018). Contrary to CDA approaches, the semiotics of science is concerned with the subtle power of modalization that works through weak modalities. In the public communication of scientific knowledge associated with risks, we are not only confronted with the problem of strong modality, but also with the power of weak modality. Weak modality not only is used as a way to protect science from becoming dogmatic and antiscientific, but it also carries the risk of appearing publicly weak in its epistemic assertions. This weakness is, however, necessary when there is a risk involved, that is when there is a certain uncertainty of danger.

The data consist of three news articles: a piece from the BBC about new advice from the World Health Organization (WHO) on the general need to use a mask although previously this was deemed unnecessary (Triggle, 2020); an online news piece from Euronews that tried to counteract previous news about the protective role of tobacco in COVID-19 infections (Holroyd, 2020); and finally a news piece from TIME magazine that corrected the claim of Maria Van Kerkhove, a technical leader at WHO that the asymptomatic transmission of COVID19 was rare (Ducharme, 2020). What these three pieces have in common is that they do not constitute corrections of wrong information but correct the incertitude of scientific information that is associated with risk. Instead of attempting to say that something in the past was wrong, these pieces are trying to shift the role of uncertainty to manage the risk communicated. In other words, the corrected information is not more certain but is believed to be less risky. The choice of these three documents is based on three methodological principles derived from CDA (Wodak and Meyer, 2009) that define what makes a text relevant to be analyzed in terms of society-discourse relations: (1) they are public and widely spread discourses, which makes them relevant for the study of the relations between society and discourse; (2) they are produced by powerful media institutions that play an important role in framing and determining the agenda-setting of topics in the public sphere; and (3) they represent different geographies of news media production and thus assure plurality in the analysis. The selected articles are accessible online, which increases their impact in terms of the number of readers they reach; they come from three news media institutions with longstanding credibility; they represent three different geographies of news media production (The United Kingdom, Europe, and The United States of America). In terms of their adequacy for the approach to the problem of the SCCR, they present three examples of important moments of communication during the pandemic that were the object of the correction of information: the use of masks, the infection risk of smokers, and the risk of virus transmissibility.

\section{RESULTS AND DISCUSSION}

\section{Semiotic Modality in the BBC News Piece}

Modality can be a useful tool to investigate the discourse of SCCR. Instead of communicating that something is (certainly) true or (certainly) false, risk communication works in a field where a lack of certainty forces us to approach falsehood and truthfulness as relative degrees. The study of modality offers one of the ways to approach how those degrees are managed in the communication of topics that involve risk. Considering the previously stated problem, modality can be helpful for understanding how science communication uses modality to correct risk. The first question that stems from the problem is: How does SCCR modalize corrected discourse?

The BBC news article from June 6th of 2020 has a dimension of newsworthiness that is linked to a change in the position of WHO regarding the use of mask. In the following extract, the underline text represents the semiotic moves used to mark that change, and the bolded words indicate when a modality is used to produce a variation in the degree of certitude about risk:

Coronavirus: WHO advises to wear masks in public areas The World Health Organization (WHO) has changed its advice on face masks, saying they should be worn in public where social distancing is not possible to help stop the spread of coronavirus. The global body said new information showed they could provide "a barrier for potentially infectious droplets." Some countries already recommend or mandate face coverings in public. The WHO had previously argued there was not enough evidence to say that healthy people should wear masks. However, WHO director-general Dr. Tedros Adhanom Ghebreyesus said on Friday that "in light of evolving evidence, the WHO advises that governments should encourage the general public to wear masks where there is widespread transmission and physical distancing is difficult, such as on public transport, in shops or in other confined or crowded environments." (...) The organization had always advised that medical face masks should be worn by people who are sick and by those caring for them. The organization said its new guidance had been prompted by studies over recent weeks. (...). At the same time, the WHO 
stressed that face masks were just one of a range of tools that could be used to reduce the risk of transmission-and that they should not give people a false sense of protection. "Masks on their own will not protect you from Covid-19," Dr. Tedros said.

One important quantitative result of the analysis of this article is the high number of modalizers, or words that play a semiotic role in modalizing the certitude of statements, in comparison to the small number of words that signal a change in risk communication. This result will be a common trait in all the three analyzed articles. The change of the position of the WHO is justified by new scientific evidence that was not available in the past. Interestingly, this new evidence is also presented in modalized terms: the infectious droplets are "potentially" infectious (not absolutely), and the evidence is "evolving" (instead of being final evidence). This concern with modalization is clear from the role of the WHO as "advisor": the word "advice" and its variations appear four times. Instead of merely creating an obligation, the use of modality of the author encourages the use of masks ("should" appears four times). The effects of wearing a mask are presented in a semiotically weakened way: the masks "help stop" (instead of simply stop), they "could" be a barrier, and they may "reduce the risk" (instead of eliminating it). This modalization of the effects of mask wearing is then finalized with a quote from a specialist. Dr. Tedros claims that the sole use of masks "will not" protect people, which shows that the reversal of risk communication in this BBC piece is not total. Masks should be used, but they can also not be trusted as a unique solution. Wearing a mask is not an absolute risk eraser, because it is "just one" protective resource among others. The most interesting result of this analysis is that the correction of a previous communication of risk is not a "zero-sum" game, which illustrates the "risky" character of this type of communication. The WHO has "always advised" (this is strongly modalized advice, instead of "sometimes advised") that some particular individuals should wear masks. Masks can, however, give a "false sense" of protection, which is strongly modalized information because it is "false" (instead of "probably" false). The expression "false sense of protection" (which is abundantly present in news media coverage about COVID-19), acutely encapsulates the problem of modalization in risk communication: you should use a mask to be potentially protected, but the mask should not give you the feeling that you are protected. This analysis is exemplary in showing modalization as an important semiotic device to present risk information and to counter previous information about risk. However, it also shows that modalization opens the way for "partial reversions" of risk information. This communication practice gives space for contrary information without fully denying the original statement. Our analysis unveils a discourse that can be corrected without ceasing to be partially correct. Modalization shows that a news article, which reverts previous information about risk, can just be a modalization of already modalized risks. In terms of the present research problem, modalization of risk can lead to the communication of an absolute risk (there will always be some risk) or to an absence of risk (this risk will be reverted in the future). However, there is a need to study modalization beyond the word level to answer the problem of the SCCR.

In terms of a Foucauldian discourse-power analysis, semiotic analysis shows that modalizers produce a struggle for meaning that can be reappropriated and used against its original use. This possibility of struggle happens through discourse when actors use words to "invert their meaning, and redirect them against those who had initially imposed them" (Foucault, 1977, p. 151). In the case of the $\mathrm{BBC}$ article, the $\mathrm{WHO}$ of the present inverts a modality against the $\mathrm{WHO}$ of the past to guarantee its power of enunciating the level of risk in the future. To produce a weak modality about risk opens the way to revert that modality without losing the power to establish risk in the future, which means that the WHO is "always partially" correct. The power of the modality of risk operates more effectively through flexible and strategic reversibility, meaning a "certain incertitude" of change, than by the imposition of a strong certitude that could be entirely rejected in the future. This type of dynamic struggle operates through reversible words and also through words that have a weak modality. As Motta-Roth and dos Santos Lovato (2011) argued, science in the media is prone to discursive modalization, which shows the open character of science. In the case of questions of risk, this modalization seems to leave everything at the same level of risk. The correction of information was already presupposed by the corrected modalization, and the correcting modalization protects itself from future corrections. This process produces a discursive layer that protects against political responsibility while it retains the power to enunciate risk in the future. In this case, power does not work by dictating the necessity of something or by reducing possibilities (what Foucault, 1978 called the "repressive hypothesis"). The WHO instead says that the future will be different. Through its use of weak modality, the power of scientific-medical policy of the WHO extends through the future. The organization is thus protected from radical contestation by enabling flexible changes in the open field of possibilities. This intense use of modalization presents a good example of the second version of post-truth. We are not dealing with a question of lying or deceiving, but with managing the political implications and power effects of correcting information in a way that does not destroy the political credibility of the WHO to make more uncertain assertions about risk in the future. The WHO is thus engaged in a fight to be associated with the truth in the future.

The $\mathrm{BBC}$ news article, however, gives more linguistic cues to understand risk management in science communication. One of them is the modalized modus operandi of the WHO that seems to be, by its institutional configuration and international role in the government of health, a "modal institution." The WHO is an "advisor" and implies that it advises through "possibilities" (e.g., "countries can or should do that"). The WHO is not a legislator or producer of new scientific knowledge (e.g., the law is necessarily this; our scientific results resulted necessarily in this). Another relevant clue concerns a change of position that seems justified by a new situation, namely when the author claims that masks "should be worn in public where social distancing is not possible." These two examples suggest that is not only the semiotics of modalization that plays a relevant role for the 
SCCR but also for "ethos" (the WHO) and the conditions for risk information (the impossibility of social distancing). The analysis, therefore, needs to focus on other aspects of this kind of news to understand how risk is communicated and corrected.

\section{The ethos, logos, and pathos of Risk in the Euronews Article}

The approach to the semiotics of modalization in SCCR can be enriched by analyzing how modality is present in the three rhetorical dimensions of ethos, pathos, and logos. This study analyzes how the subjects, reasons, and audience of communication are associated with more or less certainty. It also presents a rhetorical-modal analysis of another news article that shows an attempt at correcting risk. Furthermore, it provides an answer to the following question: How are pathos, ethos, and logos modalized in the correction of risk communication?

The Euronews piece was published on May 7th, 2020 and focuses on the controversy concerning the low probability of COVID-19 infection in smokers in comparison to nonsmokers. The article tries to reverse the risk of previous science communication. In the following excerpt, the text indicates where the reversion is semiotically marked (underlined), and the use of modalities (bold). Furthermore, the article analyzes how ethos, pathos, and logos are related to the identified modalizations.

Coronavirus and smoking: What does the World Health Organization say?

Given that tobacco use is thought to kill an estimated eight million people every year, a recent report that claimed that smokers were less likely to contract coronavirus raised eyebrows. The preliminary study, by the Pitié-Salpêtrière Hospital in Paris, stated that "current smoking status appears to be a protective factor against the infection by SARS-CoV2." Pitié-Salpêtrière Hospital wrote that "nicotine may be suggested as a potential preventive agent against COVID-19 infection," based on scientific literature and the hospital's own observations. But the study also warned that "nicotine is a drug of abuse responsible for smoking addiction." "Smoking has severe pathological consequences and remains a serious danger for health." Despite this, the new information has clouded evidence about the relationship between smoking and COVID-19, the disease caused by the novel coronavirus. So what do world health experts say? Are smokers less likely to contract the virus? No. According to the World Health Organization (WHO), those who smoke are likely to be more vulnerable to infection. "Smokers may also already have lung disease or reduced lung capacity which would greatly increase the risk of serious illness." "Conditions that increase oxygen needs or reduce the ability of the body to use it properly will put patients at higher risk of serious lung conditions such as pneumonia." Studies also show that smokers were more likely to die than non-smokers during the Middle Eastern Respiratory Syndrome (MERS) outbreak in 2012. "People who smoke have poorer lung health, so you're already starting at a poorer baseline," said Dr. Sara Kayat, a UK GP. (...) It is also theorized that smokers are more at risk of infection because of the effect tobacco can have on ACE2 (angiotensin-converting enzyme II) receptors. These gene expressions are located in human cells, and notably in the respiratory system. "COVID19 needs to sit in this receptor to spread and duplicate, and we also know that smoking can up-regulate this receptor, so it can create more of these receptors for COVID-19 to sit within," Dr. Kayat told Euronews. "It may be that this is how smoking might contribute to a higher risk of serious consequences." A report in March by the European Centre for Disease Control (ECDC) has also identified smokers as a "vulnerable group" to infection from COVID-19, due to the "higher susceptibility" of ACE2 receptors. Meanwhile, the World Health Organization have also suggested that the very act of smoking increases the possibility of virus transmission. "Fingers are in contact with lips... and smoking products such as water pipes often involve the sharing of mouthpieces and hoses, which could facilitate the transmission of COVID-19 in communal and social settings." But while smoking does has a number of negative connotations, there is little evidence to supplement this theory. "There may be higher risks of severe outcomes from COVID-19, but whether or not smokers are more likely to catch COVID-19 is still up for debate," Dr. Kayat told Euronews. "I would not suggest using smoking as a way of preventing getting coronavirus, and certainly cutting back on your use of tobacco may help." (...) A local Foundation Trust for the UK's National Health System has released information about the coronavirus that there is "an increased risk for people who smoke." "If you are going to give up smoking, this is a very good moment to do it," said Chief Medical Officer, Prof. Chris Whitty. NHS guidelines also state that smoking increases the risk of "more than 50 serious health conditions." The French Health Ministry has stated that smokers are not more of risk of contamination, but they are "more at risk of developing serious conditions." France has severely curtailed the sale of nicotine products after the recent study in Paris. Pharmacies are now limited to selling no more than 1-month supplies of any nicotine products aimed at curbing dependence on cigarettes. Meanwhile, the online sale of products has been banned altogether. The Health Ministry said the measures were taken to "prevent the health risk linked to the excessive consumption or misuse" of nicotine products by people hoping to protect themselves from COVID-19. The Pitié-Salpêtrière hospital in Paris is planning to clinically test the use of nicotine patches on hospitalized COVID-19 patients to investigate their theory. Researchers are nevertheless not encouraging citizens to take up smoking, due to other potentially fatal health risks that are involved.

Focusing on ethos, this is a text full of experts and their institutions: Pitié-Salpêtrière Hospital, the WHO, the GP Dr. Sara Kayat, the European Centre for Disease Control, the "local Foundation Trust for the UK's National Health System," Chief Medical Officer Prof. Chris Whitty, the NHS, and the French Health Ministry. There is no explicit semiotic modalization of the various ethe involved. However, this study suggests that the news article uses institutional and geographic modalization by the way it convokes the different types of ethos of the actors. The hospital evidence is counteracted by specialists from medical 
institutions (GP Sara Kayat and Chief Medical Officer Chris Whitty) who share the same expertise as the hospital. National health institutions (the NHS and French Health Ministry) and international entities (the WHO and European Centre for Disease Control) are positioned against the local evidence from Paris. This multiplication of ethos against the low risk suggested by the study of the French hospital seems to work as a strong modalization for the high risk that is communicated by this majority.

In terms of the modalization of logos, reasons, the French hospital presents its evidence in a highly modalized way. They weaken their affirmations through "preliminary" research. The hospital claims that the result "appears" to be true. Finally, the researchers from Paris express that "nicotine may be suggested as a potential preventive agent against COVID-19 infection." The researchers of the hospital, however, also stress with a strong modality that tobacco is linked to addiction, which causes "severe" diseases and is a "serious" danger for the health of people. The reasons presented in opposition to the hospital claims are expressed in a modalized way that increases their certitude. For instance, the WHO claims that smokers are "more" vulnerable, smoke will "greatly" increase risk, its users will have "serious" illnesses, the risk of severe outcomes from COVID19 will be "higher," and smokers are "more likely" to die. However, a careful reading of the article shows that these reasons do not contradict the initial evidence advanced by the Parisian hospital. Even if all opposing actors seem to agree upon the fact that the conjunction of COVID-19 symptoms and the risk of disease caused specifically by smoking contributes to a poor health outcome, that consensus is not focused on the evidence of the French hospital on the low probability of smokers catching COVID-19. The weak modalization of this probability is clear in the quotation of Dr. Kayat when she says that the issue is something that is "still up for debate." The reasons (logos) that are strongly modalized by the majority are not directed toward the probability of both smokers and non-smokers getting the virus, but mostly toward the risks of smoking once one is infected with COVID-19.

This leads to the analysis of the modalization of the pathos (the audience) of this text, which mixes two types of audiences: (1) smokers as high-risk subjects given the dangerous interaction of smoke-related diseases or vulnerabilities and the additional complications of COVID-19 once they get the virus; and (2) smokers as probable "catchers" of the virus in comparison to non-smokers. The way the two risks are mixed, the first is presented as a high risk, and the second as an unknown risk that is probably reduced according to the hospital study, seems to legitimate an intervention directed at the "audience" (smokers and potential smokers) through the political control of the availability of nicotine patches. However, this political control appears to be unjustified in terms of the risk of contagion, even if it is justified in terms of the risk of smoke-related diseases. The objective of this control, expressed in strong modalization, is to manage the dependence of smokers by "severely" reducing the offer of nicotine products and making sure that online sales are "banned altogether" to control "excessive consumption or misuse."
The weak modalization of the low risk of smokers catching COVID-19, according to the hospital study, gives rise to a news article that reinforces the modalization of other types of risk. This interaction happens because a reduced COVID-19 risk for smokers can increase the number of smokers, therefore augmenting the risk of smoke-related diseases and the risk of a poor outcome if the smokers suffer from COVID-19. In the absence of strong evidence (logos) of the probability of smokers catching COVID-19 that could be used to oppose the reasons (logos) of the French hospital, this risk communication reinforces the power of the modality of ethos (the multiplication of international experts and health institutions) and pathos (reducing the opportunities to buy nicotine). The result of this rhetorical-modal analysis of SCCR shows that the modalities of risk can be rhetorically presented in different ways and degrees according to ethos, logos, and pathos dimensions, and they need to be analyzed carefully. In the case of the Euronews article, there seem to be no reasons (logos) to justify a strong intervention directed against the audience (pathos) besides the majority of institutions and specialists (ethos) agreeing about a high risk (the poor outcome of smokers infected with the virus) that can be augmented due to the communication of the low risk of other evidence (the low probability of smokers catching COVID-19). This example shows that the opposition to the risk communication of the French hospital with the evidence of indirect risk by the majority of the actors in the text has produced a communication in which risk is absolute. Smoking is so dangerous during a pandemic that it justifies the control of the public purchase of nicotine. This approach, however, fails to address the specific risk that the French hospital study wants to emphasize.

The power relations that can be described through a rhetorical analysis of modalizers in the Euronews piece show how different agents use their medical authority to establish links with political authorities, thus producing an exchange of legitimacy and power. Foucault already studied this phenomenon in the constitution of the forensic sciences. The judicial power received epistemic authority from the Psy-sciences to understand the criminal, and these sciences obtained the power to participate in and influence judicial decisions (e.g., determining legally imputable criminals according to their mental health status) (Foucault, 1979). The risk of smoking in the context of a pandemic is strongly modalized by associating medical authorities with the political capacity to control the actions of the audience. The number of authorities (ethos) and the capacity to politically control the audience (pathos) made the risk high, not the reasons (logos). This level of risk is thus reinforced through a political-medical association. Rather than appealing to logos, the correction of risk here occurs through controlling the nicotine market. This decision is then justified by the multiplication of medical-political ethe against the freedom of choice of the audience (pathos). Although MottaRoth and dos Santos Lovato (2011) suggested that science news is dominated by scientific actors, in the Euronews article we can see different political actors (even if they are linked to scientific and health domains) participating in the news. When science is more visibly entangled with risk issues, other non-scientific actors enter the discursive field. However, this political intervention follows 
scientific advice, which legitimates political actions and gives power to science. Curiously, this struggle between ethos and the control of pathos on the effects of the reception of discourse shows that there is a mixed encounter between the first and second versions of post-truth. It is not a question of an absence of logos, but a lack of confrontation between the merits of the two reasons that carry different levels of risk: the risk of smokers contracting COVID-19 vs. the risk of a dangerous outcome for smokers once they are infected. The political-medical institutions do not know what the risk is of a smoker contracting COVID-19 (logos), but they are sure that doubt is dangerous for the public (pathos). The institutions, thus, have a presupposition about the irrationality (a lack of logos) of the public. The struggle for establishing the risk of these two scenarios is not made through evidence alone but mostly through the power of institutions (ethos) that can make the modality of risk stronger when there are doubts about reasoning (logos).

This analysis also shows that logos, pathos, and ethos are not just discursive dimensions, but they produce a network of material elements that together produce risk communication beyond its discursive character. Thus, it becomes evident that it is necessary to analyze how the materialities of risk give rise to an SCCR that is not just linguistically and rhetorically shaped. For instance, the ethos of the WHO is already a combination of past reasons (logos) of state-nations that support the institution to operate in a coordinated way in health matters. The WHO also has an already defined audience (pathos) of health-related governmental stakeholders. These elements of logos and pathos are encapsulated in the governmental advisory task of the ethos of the WHO. In the same way, rhetorical control of the behavior (pathos) of the audience through the reduction of the sale of nicotine already presupposes an ethos of the State and a logos of the rule of law. Finally, the presentation of evidence by hospitals and medical doctors (ethos) relies on the epistemic and technical capacity of biomedical experimentation (logos), which makes their ethos an epistemic authority or creates credible expertise. An identification of how the modalization of risk differs across ethos, logos, and pathos is not enough. It is also necessary to understand how risk communication is constituted in the face of the networked materialities of risk.

\section{Actor-Network Theory Analysis of Modality in the TIME Article}

Latour proposed to extend the semiotic classic focus on textual meaning with ANT, which makes semiotics a more general enterprise of finding meaning production despite its substrate, its types, and forms of materialization. By focusing on "pathbuilding or order-making or creation of directions, one does not have to specify if it is language or objects one is analyzing" with ANT (Latour, 1996, p. 377-379). This method allows, on the one hand, to approach objects as a language and as meaningful, and, on the other hand, to view languages and meanings as objects. It is this methodological move that makes a "new continuity" between language and matter possible. This move can be understood as either "to elevate things to the dignity of texts or to elevate texts to the ontological status of things" (Latour, 1996). This "new hybrid status gives to all entities both the action, variety and circulating existence recognized in the study of textual characters and the reality, solidity, externality that was recognized in things 'out of' our representations" (Latour, 1996). In short, this approach gives meaning to things and materiality to words. Playing with the title of a famous book on pragmatics, Latour claims that through ANT we can see how the world does "words with things and things with words" (Latour, 1990, p. 63). This study used ANT as a method to understand how the discursive modalities of risk became stronger or weaker through the material relations of SCCR. The question that the article address is the following: How do the networks of materialities influence modalizations in the correction of risk communication?

In the following analysis of a TIME article, the text indicate the discursive marks of the correction (underlining) and modality (bold) of SCCR. And it also indicates when the words are associated with a hyperlink to another site (with italics). Following the relational and material method of ANT in the analysis of this June 9th of 2020 article, the analysis especially focuses on the use of hyperlinks (these links materialize a relation to another place through physical servers) and on a video that is presented at the beginning of the news piece.

Unpacking the New WHO Controversy Over Asymptomatic COVID-19 Transmission

For months, researchers have warned that people without any COVID-19 symptoms could still be silent carriers of the disease, making it that much harder to get the pandemic under control-and that much more important to take precautions like social distancing and wearing a mask, even if you feel fine. So it came as a surprise when Maria Van Kerkhove, the World Health Organization's (WHO) technical lead for COVID19 , said at a press briefing on June 8 that asymptomatic transmission appears to be "very rare." Her statement came just days after the organization directed healthy people living in areas with widespread community transmission to wear fabric face masks in public to help contain the advance of the disease. In an interview with TIME following the press briefing, Van Kerkhove said she did not mean to suggest that asymptomatic people cannot spread COVID-19. "I did not say that asymptomatic cases cannot transmit; they can," Van Kerkhove says. "The question is, do they? And if they do, how often is that happening?" Van Kerkhove says there's not yet a clear answer, but the WHO's analyses suggest symptomatic individuals are responsible for most coronavirus transmission. (She also clarified during a June 9 briefing that her comments were in response to a journalist's question, and did not constitute official WHO policy). The WHO laid out its thinking in its latest guidance on face masks, which was circulated on June 5, and was based on several reports that examined COVID-19 community spread and transmission dynamics, as well as not-yet-published findings from contacttracing reports from multiple WHO member states. Few of the cited papers explicitly examined population-level asymptomatic transmission rates. One, a preprint (i.e., not-yet peer-reviewed) research review posted to the site MedRxiv 
on June 4, analyzed four previous studies (two published and two preprint) that estimated asymptomatic transmission rates. The highest estimate was a transmission rate of $2.2 \%$, suggesting "asymptomatic spread is unlikely to be a major driver of clusters or community transmission of infection." The WHO's guidance also notes that some studies that have found evidence for asymptomatic transmission had small sample sizes, which would make their findings less statistically relevant. In addition, the WHO said, some of these studies did not rule out alternative explanations for how some patients may have contracted the virus, like touching a contaminated surface. However, just last week, researchers from the Scripps Research Translational Institute published a paper estimating that asymptomatic individuals account for up to $45 \%$ of coronavirus cases, and noted that "the viral load of such asymptomatic persons has been equal to that of symptomatic persons, suggesting similar potential for viral transmission." One of the study's author's, Scripps Director Dr. Eric Topol, criticized the WHO's comments on Twitter, writing that "there are several studies not included in [the WHO's] brief statement that counter the scant data provided here." Carl Bergstrom, a biologist at the University of Washington, wrote on Twitter that the WHO's conclusions were based on "thin evidence," at least when taking into account what has been published publicly. Bergstrom also said the organization should have more clearly distinguished between people who are "truly" asymptomatic-those who never show symptoms-and those who may unwittingly spread the disease in the days before they become symptomatic. Topol's study on asymptomatic transmission found that few people who test positive without symptoms go on to develop them, but studies suggest it takes an average of 5 days after exposure to the virus for symptoms to surface. People in this phase would be considered pre-symptomatic, not asymptomatic, but it's difficult to tell the difference. "Even if truly asymptomatic spread is very rare, pre-symptomatic transmission is likely to be important," Bergstrom wrote on Twitter. "We still need to wear masks and distance to avoid spreading the virus during this period, probably concentrated in days 3-6 after infection." Van Kerkhove acknowledged that distinction when speaking with TIME after the press briefing, and added that it can be difficult to distinguish between a mildly symptomatic and asymptomatic person. Some people may not associate mild symptoms-like fatigue or muscle aches-with COVID-19, but these individuals would still technically be symptomatic and capable of spreading the virus, Van Kerkhove says. With so much uncertainty, Van Kerkhove says more research on transmission patterns and asymptomatic carriers is required. She says people should continue following public-health guidance such as wearing fabric face masks when social distancing is not possible, and should stay home if they feel unwell. Doing so, in conjunction with robust contact tracing and isolation of people with symptoms, will help keep COVID-19 spread under control, she says. "We're not ruling anything out," Van Kerkhove says. "We're not saying that [asymptomatic spread is] not happening. But we're saying more transmission is happening among symptomatic individuals. People are looking for a binary, and it's not that." Bergstrom was more direct. The WHO's statement "seems to suggest that people without symptoms don't spread COVID19," Bergstrom tweeted. "Does this mean shoppers, students, protesters, etc., don't need masks/distancing? No.”

Two types of materiality seem relevant for risk communication in this article: (1) a video of the statement that is the object of correction; and (2) the proliferation of hyperlinks in the text. After the title of the news piece, there is a 30 $s$ video of Van Kerkhove claiming that there is a low risk of transmission by asymptomatic individuals. This statement about risk information that the TIME article corrects only lasts $5 \mathrm{~s}$. The remaining $25 \mathrm{~s}$ are about the importance of tracing symptomatic individuals. In that $5 \mathrm{~s}$, we hear: it "still appears to be rare that an asymptomatic individual actually transmits onwards." This comment contradicts the "very rare" modalization that is attributed to the technical lead of the WHO in the article. In terms of the ANT analysis, the video is a visual materialization of the responsible speaker discussing risk information and produces more "veracity" in comparison to just text. This approach means that the modalization of the video materiality makes the claim stronger because we can see the person who is saying the words and have access to the authority that is associated with a WHO press conference. Given the privileged space that is given to the video, and the speed of visual media in presenting information in comparison to the textual quotation of Van Kerkhove later in the text, we can observe a form of "material modalization" that is made possible not only by the type of medium used but also by its place on the news website.

Given that in the text Van Kerkhove corrects her claims, suggested that the video is used as a "narrative of guilt" that asks to be solved later in the text. The clip can be interpreted as a type of "shame-inducing" that demands reparation. This type of risk communication foregrounds particular risks by first presenting something that has already been denied and only later offering the needed correction. The journalists could instead just have published a video with the most correct and updated information. Van Kerkhove said in her defense that her claim was a reaction to the question of a journalist and did not constitute the official policy of the WHO. The guilt narrative strategy of TIME magazine does not include the questions of the journalist, which could have provided other cues for understanding what was answered. The interaction between the WHO and the news media is a discursive materialization that constitutes one of the most important sources of public risk communication, and the interaction could have been made available. It is also interesting to note that the answer to a journalist does not constitute official policy even if this statement is made at a public briefing of the WHO. This interaction shows that risk communication is not just about communicating all types of low and high risks because there is an "official policy" that distinguishes between what is an authorized communication of risk and what not. This article is an interesting risk communication piece because it (1) states that something rarely occurs (asymptomatic transmission); (2) it corrects that information with a statement that casts doubt about its degree of occurring, and, finally, (3) it is presented 
as "unofficial" discourse because the speaker crossed a certain WHO political line about the public enunciation of risk when talking to a journalist. Van Kerkhove modalizes what is said through materialization of the speech situation: what is said by the WHO is certain, what is said to a journalist is uncertain. This situation gives us the sense that risk is institutionally negotiated, and there is a risk of talking about risks that are not officially approved. This state of affairs reveals that the enunciation of risk can also constitute the management of the authority. Thus, journalism plays a role in questioning the authority associated with official risk assessment and communication. The materiality of the video and the interaction between health authorities and journalists are important clues for the communication of risk during a pandemic that goes beyond discursive indexes. The TIME piece shows that modalization changes according to the types of media, the interaction, and the speakers involved, and the institutions that materialize the speech situation.

The hyperlinks used in the article are abundant. The piece first presents two hyperlinks to previous TIME articles concerning the advice of researchers about the need for social distancing, even from people who appear to be healthy. The statement of Van Kerkhove is contrasted with yet another hyperlink from TIME magazine about the advice of the WHO on the use of masks. The hyperlink to the advice of the WHO is also present in the text and is backed up by another hyperlink from the CDC about scientific reports that support that advice. The evidence in favor of earlier remarks of Van Kerkhove is available in a hyperlink to a non-peer-reviewed paper on medrxiv.org. This paper is, in turn, contradicted by another TIME hyperlink to a published and peer-reviewed paper. The Twitter account of a researcher (Dr. Eric Topol) is also shared, which in turn has a hyperlink to medrxiv.org where studies are available that support the evidence of the study of Topol. Another Twitter account of an expert (Carl Bergstrom) is presented, critiquing the technical statement of the WHO of not being informed by what has been published on the matter. TIME again cites another one of its articles referring to the work of Topol and includes a link to the scientific journal Nature, both of which contradict the "very rare" thesis. The last link is another hyperlink to a TIME article about the process of tracing individuals who have been infected with COVID-19.

This description of the abundant use of hypermedia links shows that the link to another text can operate as a backup justification for what is being read in the text of the article itself. The materiality of the link is an important modalization for risk communication, given its archival and testimonial character. A phrase with a link becomes more certain because it has already been reported elsewhere. Information is thus repeated and justified. The article engages with a multiplication of links to correct risk information and follows a quantitative strategy. The problem, however, is that each of these links comprises its own risk communication and modalization of uncertainty. The links to medrxiv.org or Twitter are cases in point of non-peer-reviewed information for science communication. Another important risk is linked to the economy of news media. TIME only cites its own past articles, and thereby follows the competitive logic of the news media market, instead of quoting the best information available independently of news media source. This line of action is one classic phenomenon of "gatekeeping" (Tuchman, 1978), which is systematically studied in communication research. The communication of science, therefore, not only has to deal with competing types of scientific information but also with competing news providers. The social and economic value of a news piece depends on its novelty in comparison to other media players and does not only depend on its certitude. Media competition determines the course of gatekeeping, namely by excluding important information about risk that has been made available by other sources.

The hyperlinks in the TIME article also carry the risk of being left unread and just used as a materialization of a text that can "act." In other words, it may "conduct" us to other texts that legitimize what is being currently said. This sequencing demands an extremely active reader if he/she is to follow all the links that are offered to him/her. Concerning the general problem of the communication of risks that does not engage in either communication free of risk or unjustifiably exacerbates risk, this ANT analysis shows that the TIME article tries to produce a balanced narrative through the display of diverse links and the different claims of Van Kerkhove. However, the way the article uses video and hyperlink resources may produce a form of communication of risk that downplays the risk involved too much. The video shaming strategy suggests that it is easy to make a judgment about the risk and uncertainty of scientific information, and it is not complicated to find culpable individuals. The hyperlinks demand an active reader who follows the justifications for what is being read and create the impression that they are risk-free archives of testimony.

In terms of an analysis of the power effects of discourse, the journalists correct information about COVID-19 while they are in a power relation with official sources. This struggle extends to biomedical researchers who contest the level of risk conveyed by the WHO. The media in question also tries to produce a discourse of risk that takes into consideration the tactics, strategies, and powers of media competition in a market of information. The case of TIME magazine seems to be an example of science communication characterized by the first version of a post-truth situation. Apparently, it is a text in which the question of falsity seems to be pervasive. Two elements seem to justify this reading. Although the WHO spokesperson said something that is not true according to the existing scientific evidence, the media also did not quote the right modal word that the spokesperson used. The opportunity that the spokesperson was given to correct the information of risk showed that this was a moment of struggle through the exigence of truth. This case, therefore, also applies to the second version of post-truth. A fight concerning truth, and not falsity, characterizes the struggle between scientists who produce scientific evidence and the WHO as the institution that decides to use that evidence to recommend courses of action. These various actors use the truth to fight for the definition of the level of risk. 


\section{CONCLUSION}

Science communication is in many ways a daughter of risk. The German historian Koselleck (1988, p. 1; 7-8) famously suggested that there is a connection between the concepts of "critique" and "crisis" in the Enlightenment discourse of the 18th century. These concepts were used during a time when knowledge was important for criticizing absolutist regimes that were in crisis. Communication studies are also immersed in this conceptual history because it has been strongly linked to a critique of political mass propaganda, especially during the Cold War crisis. Military tension motivated the research and critique of "mass media effects" and their role in mobilizing people for war efforts (Glander, 2000). Science communication, which follows the Enlightenment tradition and Communication Studies concerns with political effects, shares this conceptual nexus of crisis and critique. The communication of science became more urgent due to a need to repair the crisis in public trust and financing during the post-war period, given that science had played a decisive and criticized role in war efforts (Miller, 2001). Investment to increase the number of scientifically literate people, in order to make them adapt to a more sophisticated industry, also reduces the risk of unemployment. The fight against national and international economic stagnation was thus an important motive for investing in science communication (Shamos, 1995). The communication crisis associated with Genetically Modified Organisms has shown the limits of approaches based on the public intake of scientific facts without a dialog on ethical, economic, political, and social matters (House of Lords, 2000). Finally, science communication has newly faced crisis and critique through recent issues of post-truth (Reyna, 2020), fake news (Scheufele and Krause, 2019), and the denialism of science (Oreskes and Conway, 2010). The current pandemic is an urgent topic for communication research because as a situation of crisis it creates and demands critique and is immersed in the posttruth phenomenon. The virus is not only a source of risk for public health and communication strategies (Cuan-Baltazar et al., 2020; Krause et al., 2020, p. 19; Li et al., 2020), but the proper idea of truth and scientific evidence was also already at risk during the post-truth crisis. Thus, we are facing a double risk with the science communication on COVID-19. Taking into consideration this double risk, it is important to understand how risk about COVID-19 has been communicated in the news media.

The three types of textual analyses proposed in this article give us three important results about how risk correction in news media of COVID-19 topics is modalized. The results highlight how difficult it is to correct risk information without producing more risk or devaluing relevant risk. In the first case (the BBC), a simple modal analysis showed that a modalized risk can always be reverted or partially correct, which makes the role of SCCR textually challenging. The second case (Euronews) presented the difficulties of managing risk when different types of risk are combined. In this article, the reasons (logos) of certain risks were overlooked due to the prominent use of the ethos and pathos dimensions of risk. The last case (TIME) focused on the importance of the materialities of risk communication, namely the use of video and hyperlinks that can increase the amount of risk involved.

The analysis of semiotic, rhetorical, and material modalities has proven to be productive. (1) Semiotically, the number of modal words is higher than the words that express the change of the corrected information. This finding suggests that the correction does not totally reverse previous information but introduces uncertainty to protect the author from communicating information that could be heavily corrected in the future. The interesting result is that the correction of risk can be characterized by a strategy of inserting more, not less, uncertainty. (2) In rhetorical terms, when there is a correction of information, the ethos and pathos dimensions of discourse can be more prominent than the discursive dimension of logos. It could be expected that logos, reason, would be the more relevant discursive element because it is logos, or rationality, that is supposed to require correction when things are uncertain and risky. However, the result indicates a proliferation of the "social" dimensions of discourse, namely ethos and pathos. The correction of information is about more than just correcting facts and reasons, and the social dimension of science communication shows that it is not just a question of literacy or understanding. (3) In terms of a socio-material analysis of discourse, a recourse to the materiality of hyperlinks can increase, instead of reducing, the risk that the correction of information tried to counteract. A multiplication of sources of information does not just add more backup information. The hyperlinks in the TIME piece are accompanied by the uncertainties that those sources carry. Although these hyperlinked sources are not visible, they demand additional interpretative work from the reader. Readers, thus, need to follow and compare the different links and how they really justify one another.

This study concludes by identifying the political implications that the results present while focusing on the problems associated with the communication of uncertainty and risk. The science communication on uncertainty and risk needs to be understood along with the topic of post-truth, as presented in its second version. The problems of communicating uncertainty and risk could be associated with the issue of revealing "too much truth" that can negatively impact some vulnerable publics (as is the case in the Euronews article). As such the Euronews article offers an example of the problems of communicating uncertainty to audiences that are prone to be suspicious of science (as is the case in a post-truth situation). However, these problems will provide limited options for debate if we do not take seriously the thesis that the communication of science is inevitably associated with power effects and political consequences. This means that the problem of communicating uncertainty and risk needs to take into consideration the power associated with the communication of different degrees of uncertainty and risk. That is, we need to analyze who will lose and who will win. Will scientific institutions maintain their social capital of trust if they disclose uncertainties that could produce political contestation? Which audiences will benefit from or be harmed by that disclosure or hiding of uncertainty? When should publics or scientific institutions ask for more power to question uncertainty? To answer these questions, it is not enough to study the production 
of news but it is also necessary to study the reception of news. How do different audiences interpret and reappropriate the levels of risk and uncertainty that are in dispute during the correction of risk during the COVID-19 crisis? Recent research suggests that a lack of consensus among experts produces more public distrust than uncertainty in terms of data (Gustafson and Rice, 2020). This is an important insight for understanding what could be the effects of the Euronews piece, given that the consensus among the different ethe trumped the discussion of evidence.

It is difficult to believe that it will be possible to communicate uncertainty and risk without taking into consideration the political and power effects associated with a complex pandemic situation. More importantly, it is not advised to do so. Our posttruth situation demands that we should be cautious concerning the intended and unintended power effects of science and its communication. This analysis has already shown how a simple language function, modality, that is used to control and correct risk does not cease to produce possibilities of augmenting that risk. This persistence of risk correlates with power effects. In the case of the $\mathrm{BBC}$ news piece, this irreducible level of risk shows how the WHO tries to maintain its power as an advisor. The WHO enunciates risk through its use of modalities that protect it from losing its power to advise in the future. The Euronews example clearly showed how the uncertainty of risk about potentially dangerous information more strongly mobilized the ethos dimension of discourse against certain dangerous reasons (logos), than introducing a multiplication of reasons. In addition, the control of the effects of the reasons on the audience (pathos), by reducing its liberty of choice through market restrictions, is a clear political intervention with regard to reducing risk. Finally, the TIME news piece shows a struggle among three dimensions: (1) a fight for what constitutes "official" risk enunciation during

\section{REFERENCES}

Amazeen, M. A. (2020). Journalistic interventions: the structural factors affecting the global emergence of fact-checking. Journalism 21, 95-111. doi: $10.1177 / 1464884917730217$

Amidon, T. R., Nielsen, A. C., Pflugfelder, E. H., Richards, D. P., and Stephens, S. H. (2021). visual risk literacy in "Flatten the Curve" COVID-19 visualizations. J. Bus. Tech. Commun. 35, 101-109. doi: 10.1177/1050651920963439

Ancarno, C. (2015). When are public apologies "successful"? Focus on British and French apology press uptakes. J. Pragmat. 84, 139-153. doi: 10.1016/j.pragma.2015.04.015

Angermuller, J. (2018). Truth after post-truth: for a strong programme in discourse studies. Palgrave Commun. 4, 1-8. doi: 10.1057/s41599-018-0080-1

Aristotle (1984). The Complete Works of Aristotle: The Revised Oxford Translation. Princeton University Press.

Atherton, R. (2021). "Missing/Unspecified": demographic data visualization during the COVID-19 pandemic. J. Bus. Tech. Commun. 35, 80-87. doi: $10.1177 / 1050651920957982$

Batova, T. (2021). "Picturing" Xenophobia: visual framing of masks during COVID-19 and its implications for advocacy in technical communication. J. Bus. Tech. Commun. 35, 50-56. doi: 10.1177/1050651920958501

Bazerman, C. (1988). Shaping Written Knowledge - The Genre and Activity of the Experimental Article in Science. Wisconsin: The University of Wisconsin Press.

Beck, U. (1992). Risk Society: Towards a New Modernity. London: SAGE Publications. the interaction with journalists and a WHO advisor; (2) a display of the logic of the economy of attention that is associated with the competitive behavior of news media that privilege their own information; and (3) the struggle that different biomedical researchers have with the WHO to establish an appropriate level of risk. We can suggest from this qualitative study that the correction of risk communication should not just be the addition of modalizers, or the need to scrutinize how the three rhetorical modes influence the degree of that modalization, or point us to being careful concerning the impact of online materialities of communication. We also need to take into consideration political implications, power effects, the effect that the correction of risky information has on different publics, scientific institutions, political decisions, and media. Who sets the risk? What risks can be contested? Where can we discuss them? When can we debate the risks? How can we determine the risk?

\section{DATA AVAILABILITY STATEMENT}

The original contributions presented in the study are included in the article/supplementary material, further inquiries can be directed to the corresponding author/s.

\section{AUTHOR CONTRIBUTIONS}

The author confirms being the sole contributor of this work and has approved it for publication.

\section{FUNDING}

This work was supported by the Portuguese Foundation for Science and Technology (FCT) under grant SFRH/BD/120675/2016 to fund a Ph.D.

Bronstein, M. V., Pennycook, G., Bear, A., Rand, D. G., and Cannon, T. D. (2019). Belief in fake news is associated with delusionality, dogmatism, religious fundamentalism, and reduced analytic thinking. J. Appl. Res. Mem. Cogn. 8, 108-117. doi: 10.1016/j.jarmac.2018. 09.005

Chan, C. K. (2016). Defining health risk by media template: Hong Kong's news discourse of the Swine Flu pandemic. Journalism 17, 1018-1036. doi: 10.1177/1464884915595473

Chen, K., Bao, L., Shao, A., Ho, P., Yang, S., Wirz, C., et al. (2020). How public perceptions of social distancing evolved over a critical time period: Communication lessons learnt from the American state of Wisconsin. JCOM J. Sci. Commun. 19:A11. doi: 10.22323/2.19050211

Chou, W. Y. S., and Budenz, A. (2020). Considering emotion in COVID-19 vaccine communication: addressing vaccine hesitancy and fostering vaccine confidence. Health Commun. 35, 1718-1722. doi: 10.1080/10410236.2020.1838096

Cooper, M. E. (2008). Life As Surplus: Biotechnology and Capitalism in the Neoliberal Era, 1st Edn. University of Washington Press.

Cuan-Baltazar, J. Y., Muñoz-Perez, M. J., Robledo-Vega, C., Pérez-Zepeda, M. F., and Soto-Vega, E. (2020). Misinformation of COVID-19 on the Internet: Infodemiology Study. JMIR Public Health Surveillance 6:e18444. doi: $10.2196 / 18444$

Davies, S. R. (2019). Science communication is not an end in itself: (Dis)assembling the science festival. Int. J. Sci. Educ. B Commun. Public Engag. 9, 40-53. doi: $10.1080 / 21548455.2018 .1540898$ 
Ducharme, J. (2020). Unpacking the New WHO Controversy Over Asymptomatic COVID-19 Transmission. Time. Retrieved from: https://time.com/5850256/who-asymptomatic-spread/ (accessed June 25, 2020).

Fahnestock, J. (2020). Rhetorical Citizenship and the Science of Science Communication. Argumentation 34, 371-387. doi: 10.1007/s10503-019-09499-7

Foucault, M. (1971). Orders of discourse. Soc. Sci. Inform. 10, 7-30. doi: $10.1177 / 053901847101000201$

Foucault, M. (1977). "Nietzsche, genealogy, history," in Language, CounterMemory, Practice: Selected Essays and Interviews, ed D. Bouchard (Ithaca, NY: Cornell University Press).

Foucault, M. (1978). The History of Sexuality Volume 1: An Introduction. New York, NY: Pantheon Books.

Foucault, M. (1979). Discipline and Punish: The Birth of the Prison. New York, NY: Vintage Books.

Fu, K., and Zhu, Y. (2020). Did the world overlook the media's early warning of COVID-19? J. Risk Res. 23, 1-5. doi: 10.1080/13669877.2020.1756380

Fuller, S. (2018). Post-Truth: Knowledge as a Power Game. London; New York, NY: Anthem Press. doi: 10.2307/j.ctvgd30v

Glander, T. (2000). Origins of Mass Communications Research During the American Cold War: Educational Effects and Contemporary Implications. Mahwah, NJ, London: Lawrence Erlbaum Associates.

Grace, R., and Tham, J. C. K. (2021). Adapting uncertainty reduction theory for crisis communication: guidelines for technical communicators. J. Bus. Tech. Commun. 35, 110-117. doi: 10.1177/1050651920959188

Graham, S. S. (2021). Misinformation inoculation and literacy support tweetorials on COVID-19. J. Bus. Tech. Commun. 35, 7-14. doi: $10.1177 / 1050651920958505$

Graves, L. (2018). Boundaries not drawn: mapping the institutional roots of the global fact-checking movement. Journal. Stud. 19, 613-631. doi: 10.1080/1461670X.2016.1196602

Guan, D., Wang, D., Hallegatte, S., Davis, S. J., Huo, J., Li, S., et al. (2020). Global supply-chain effects of COVID-19 control measures. Nat. Hum. Behav. 4, 577-587. doi: 10.1038/s41562-020-0896-8

Gustafson, A., and Rice, R. E. (2020). A review of the effects of uncertainty in public science communication. Public Understanding of Science. 29, 614-633. doi: $10.1177 / 0963662520942122$

Guttman, N., and Lev, E. (2020). Ethical issues in COVID-19 communication to mitigate the pandemic: dilemmas and practical implications. Health Commun. 36, 116-123. doi: 10.1080/10410236.2020.1847439

Head, K. J., Kasting, M. L., Sturm, L. A., Hartsock, J. A., and Zimet, G. D. (2020). A national survey assessing SARS-CoV-2 vaccination intentions: implications for future public health communication efforts. Sci. Commun. 42, 698-723. doi: $10.1177 / 1075547020960463$

Heffernan, C., Misturelli, F., and Thomson, K. (2011). The representation of highly pathogenic avian influenza in the Chinese media. Health Risk Soc. 13, 603-620. doi: 10.1080/13698575.2011.630719

Hendriks, F., and Jucks, R. (2020). Does scientific uncertainty in news articles affect readers' trust and decision-making? Media Commun. 8, 401-412. doi: $10.17645 /$ mac.v8i2.2824

Hendriks, F., Kienhues, D., and Bromme, R. (2020). Replication crisis = trust crisis? The effect of successful vs failed replications on laypeople's trust in researchers and research. Public Understand. Sci. 29, 270-288. doi: $10.1177 / 0963662520902383$

Holroyd, M. (2020). Coronavirus and smoking: What does the WHO say? Euronews. Retrieved from: https://www.euronews.com/2020/05/07/ covid-19-and-smoking-what-does-the-who-say (accessed June 25, 2020).

Hope, L. (2021). Protecting pandemic conversations: tracing twitter's evolving content policies during COVID-19. J. Bus. Tech. Commun. 35, 88-93. doi: $10.1177 / 1050651920958393$

House of Lords (2000). Select Committee on Science and Technology, Third Report: Science and Society. London: HMSO.

Jasanoff, S., and Simmet, H. R. (2017). No funeral bells: Public reason in a 'post-truth' age. Soc. Stud. Sci. 47, 751-770. doi: 10.1177/0306312717731936

Kampf, Z. (2011). Journalists as actors in social dramas of apology. Journalism 12, 71-87. doi: $10.1177 / 1464884910385190$
Klemm, C., Das, E., and Hartmann, T. (2016). Swine flu and hype: a systematic review of media dramatization of the H1N1 influenza pandemic. J. Risk Res. 19, 1-20. doi: $10.1080 / 13669877.2014 .923029$

Koerber, A. (2021). Is it fake news or is it open science? science communication in the COVID-19 pandemic. J. Bus. Tech. Commun. 35, 22-27. doi: 10.1177/1050651920958506

Koselleck, R. (1988). Critique and Crisis: Enlightenment and the Pathogenesis of Modern Society. Cambridge, MA: MIT Press.

Krause, N. M., Freiling, I., Beets, B., and Brossard, D. (2020). Fact-checking as risk communication: The multi-layered risk of misinformation in times of COVID-19. J. Risk Res. 23, 1-8. doi: 10.1080/13669877.2020.17 56385

Kuhn, T. (1970). The Structure of Scientific Revolutions, 2nd Edn, Enlarged. Chicago; London: The University of Chicago Press.

Lasser, J., Ahne, V., Heiler, G., Klimek, P., Metzler, H., Reisch, T., et al. (2020). Complexity, transparency and time pressure: Practical insights into science communication in times of crisis. JCOM J. Sci. Commun. 19:N01. doi: $10.22323 / 2.19050801$

Latour, B. (1990). "The force and the reason of experiment," in Experimental Inquiries: Historical, Philosophical and Social Studies of Experimentation in Science, ed H. E. Le Grand (Dordrecht: Kluwer Academic Publishers), 49-80. doi: 10.1007/978-94-009-2057-6_2

Latour, B. (1996). On actor-network theory: a few clarifications. Soziale Welt 47 , 369-381.

Latour, B. (1999). On recalling ANT. Sociol. Rev. 47(Suppl. 1), 15-25. doi: 10.1111/j.1467-954X.1999.tb03480.x

Latour, B., and Bastide, F. (1986). "Writing science-fact and fiction: the analysis of the process of reality construction through the application of sociosemiotic methods to scientific texts," in Mapping the Dynamics of Science and Technology Mapping the Dynamics of Science and Technology, eds M. Callon, J. Law, and R. Arie (London: Macmillan), 51-66. doi: 10.1007/978-1-349-07 408-2_4

Latour, B., and Woolgar, S. (1986). Laboratory Life: The Construction of Scientific Facts. Princeton University Press. doi: 10.1515/9781400820412

Li, H. O. Y., Bailey, A., Huynh, D., and Chan, J. (2020). YouTube as a source of information on COVID-19: a pandemic of misinformation? BMJ Glob Health 5:e002604. doi: 10.1136/bmjgh-2020-002604

Lovari, A. (2020). Spreading (Dis)Trust: Covid-19 misinformation and government intervention in Italy. Media Commun. 8, 458-461. doi: $10.17645 /$ mac.v8i2.3219

Lowrey, C. H., and Venkatesan, P. (2008). Making science accessible: a semiotics of scientific communication. Biosemiotics 1, 253-269. doi: 10.1007/s12304-008-9017-1

Maeseele, P. (2015). Risk conflicts, critical discourse analysis and media discourses on GM crops and food. Journalism 16, 278-297. doi: $10.1177 / 1464884913511568$

Manyweathers, J., Taylor, M., and Longnecker, N. (2020). Expertise and communicating about infectious disease: a case study of uncertainty and rejection of local knowledge in discourse of experts and decision makers. JCOM J. Sci. Commun. 19:A01. doi: 10.22323/2.19040201

Martini, C. (2018). Ad Hominem arguments, rhetoric, and science communication. Stud. Log. Gramm. Rhetor. 55, 151-166. doi: 10.2478/slgr-2018-0033

Meese, J., Frith, J., and Wilken, R. (2020). COVID-19, 5G conspiracies and infrastructural futures. Media Int. Australia 177, 30-46. doi: $10.1177 / 1329878 X 20952165$

Meyer, M. (2010). The Brussels school of rhetoric: from the new rhetoric to problematology. Philos. Rhetor. 43, 403-429. doi: 10.1353/par.2010.0007

Miller, C. R. (2003). The presumptions of expertise: The role of ethos in risk analysis. Configurations 11, 163-202. doi: 10.1353/con.2004.0022

Miller, S. (2001). Public understanding of science at the crossroads. Public Understand. Sci. 10, 115-120. doi: 10.1088/0963-6625/10/1/308

Motta-Roth, D., and dos Santos Lovato, C. (2011). The hegemonic power of science in the scientific popularization discourse. Calidoscopio 9, 251-268. doi: $10.4013 /$ cld.2011.93.09

Mukerji, C. (2014). A Fragile Power: Scientists and the State. Princeton, NJ: Princeton University Press. 
Myers, G. (2003). Discourse studies of scientific popularization: questioning the boundaries. Discourse Stud. 5, 265-279. doi: 10.1177/1461445603005002006

Nhung, L. T. K. (2018). Representation(s) of developed and developing countries in newspapers' coverage of climate conferences: a critical discourse analysis. Int. J. English Linguist. 8, 35-47. doi: 10.5539/ijel.v8n2p35

Opt, S. K. (2013). Apology as power intervention: the case of news of the world. West. J. Commun. 77, 424-443. doi: 10.1080/10570314.2013.767471

Oreskes, N., and Conway, E. M. (2010). Merchants of Doubt: How a Handful of Scientists Obscured the Truth on Issues From Tobacco Smoke to Global Warming. New York, NY: Bloomsbury Publishing.

Paek, H. J., and Hove, T. (2020). Communicating uncertainties during the COVID-19 outbreak. Health Commun. 35, 1729-1731. doi: $10.1080 / 10410236.2020 .1838092$

Palliser, A., and Dodson, G. (2019). Avoiding post-truth environmental conflict in New Zealand: Communicating uncertainties in endangered species science. JCOM J. Sci. Commun. 18:A05. doi: 10.22323/2.18040205

Patel, S. S., Moncayo, O. E., Conroy, K. M., Jordan, D., and Erickson, T. B. (2020). The landscape of disinformation on health crisis communication during the COVID-19 pandemic in Ukraine: Hybrid warfare tactics, fake media news and review of evidence. JCOM J. Sci. Commun. 19:A02. doi: 10.22323/2.19050202

Popper, K. R. (2002). The Logic of Scientific Discovery. London; New York, NY: Routledge. doi: 10.1063/1.3060577

Post, S. (2016). Communicating science in public controversies: strategic considerations of the German climate scientists. Public Understand. Sci. 25, 61-70. doi: 10.1177/0963662514521542

Pulido, C. M., Villarejo-Carballido, B., Redondo-Sama, G., and Gomez, A. (2020). COVID-19 infodemic: more retweets for science-based information on coronavirus than for false information. Int. Sociol. 35, 377-392. doi: $10.1177 / 0268580920914755$

Reyna, V. F. (2020). "A scientific theory of gist communication and misinformation resistance, with implications for health, education, and policy," in Proceedings of the National Academy of Sciences, 36, 116-123. doi: 10.1073/pnas.1912441117

Rorty, R. (1992). The Linguistic Turn: Essays in Philosophical Method. Chicago; London: University of Chicago Press.

Sarathchandra, D., and McCright, A. M. (2017). The effects of media coverage of scientific retractions on risk perceptions. Sage Open 7:2158244017709320. doi: $10.1177 / 2158244017709324$

Scheufele, D. A., and Krause, N. M. (2019). Science audiences, misinformation, and fake news. Proc. Natl. Acad. Sci. U.S.A. 116, 7662-7669. doi: 10.1073/pnas.1805871115

Shamos, M. H. (1995). The Myth of Scientific Literacy. New Brunswick, NJ: Rutgers University Press.

Simmerling, A., and Janich, N. (2016). Rhetorical functions of a language of uncertainty' in the mass media. Public Understand. Sci. 25, 961-975. doi: $10.1177 / 0963662515606681$

Simon, N. (2020). Investigating ethos and pathos in scientific truth claims in public discourse. Media Commun. 8, 129-140. doi: 10.17645/mac.v8i1.2444

Smith, C. N., and Seitz, H. H. (2019). Correcting misinformation about neuroscience via social media. Sci. Commun. 41, 790-819. doi: $10.1177 / 1075547019890073$

Stamou, A. G., Lefkaditou, A., Schizas, D., and Stamou, G. P. (2009). The discourse of environmental information: representations of nature and forms of rhetoric in the information center of a Greek reserve. Sci. Commun. 31, 187-214. doi: $10.1177 / 1075547009335347$
Stengers, I. (2000). The Invention of Modern Science. New York, NY: University of Minnesota Press.

Szymanski, E. (2016). Enacting multiple audiences: science communication texts and research-industry relationships in the New Zealand wine industry. Sci. Commun. 38, 724-745. doi: 10.1177/1075547016677042

Tollefson, J. W. (2014). The discursive reproduction of technoscience and Japanese national identity in The Daily Yomiuri coverage of the Fukushima nuclear disaster. Discourse Commun. 8, 299-317. doi: 10.1177/17504813135 10817

Triggle, N. (2020). Wear Masks in Public, WHO Says in New Advice. BBC News. Retrieved from: https://www.bbc.com/news/health-52945210 (accessed June $25,2020)$.

Tuchman, G. (1978). Making News: A Study in the Construction of Reality. New York, NY: The Free Press.

van Barneveld, K., Quinlan, M., Kriesler, P., Junor, A., Baum, F., Chowdhury, A., et al. (2020). The COVID-19 pandemic: lessons on building more equal and sustainable societies. Econom. Lab. Relat. Rev. 31, 133-157. doi: $10.1177 / 1035304620927107$

Van Heekeren, M. (2020). The curative effect of social media on fake news: a historical re-evaluation. Journal. Stud. 21, 306-318. doi: 10.1080/1461670X.2019.1642136

Vraga, E. K., and Bode, L. (2017). Using expert sources to correct health misinformation in social media. Sci. Commun. 39, 621-645. doi: $10.1177 / 1075547017731776$

Waisbord, S. (2018). The elective affinity between post-truth communication and populist politics. Commun. Res. Pract. 4, 17-34. doi: 10.1080/22041451.2018.1428928

Wittgenstein, L. (1991). On Certainty. London: Wiley-Blackwell.

Wodak, R., and Meyer, M. (2009). Methods for Critical Discourse Analysis. London: SAGE.

Wynne, B. (1992). Misunderstood misunderstanding: social identities and public uptake of science. Public Understand. Sci. 1, 281-304. doi: 10.1088/0963-6625/1/3/004

Wynne, B. (1998). "May the sheep safely graze? A reflexive view of the expertlay knowledge divide," in Risk, Environment and Modernity: Towards a New Ecology, eds S. Lash, B. Szerszynski, and B. Wynne (London: SAGE Publications Ltd), 44-83. doi: 10.4135/9781446221983.n3

Wynne, B. (2002). Risk and environment as legitimatory discourses of technology: reflexivity inside out? Curr. Sociol. 50, 459-477. doi: $10.1177 / 0011392102050003010$

Zhai, F., Zhai, Y., Cong, C., Song, T., Xiang, R., Feng, T., et al. (2020). Research progress of coronavirus based on bibliometric analysis. Int. J. Environ. Res. Public Health 17:3766. doi: 10.3390/ijerph17113766

Conflict of Interest: The author declares that the research was conducted in the absence of any commercial or financial relationships that could be construed as a potential conflict of interest.

Copyright (๑) 2021 Fernandes. This is an open-access article distributed under the terms of the Creative Commons Attribution License (CC BY). The use, distribution or reproduction in other forums is permitted, provided the original author(s) and the copyright owner(s) are credited and that the original publication in this journal is cited, in accordance with accepted academic practice. No use, distribution or reproduction is permitted which does not comply with these terms. 